University of Wollongong

Research Online

Centre for Multicultural Studies Occasional

Papers

Faculty of Arts, Social Sciences \& Humanities

1987

\title{
The inherent subjectivity of the apparently objective in research on ethnicity and class
}

Stephen Castles

University of Wollongong

A Jakubowicz

University of Wollongong

Follow this and additional works at: https://ro.uow.edu.au/cmsocpapers

\section{Recommended Citation}

Castles, Stephen and Jakubowicz, A, The inherent subjectivity of the apparently objective in research on ethnicity and class, Centre for Multicultural Studies, University of Wollongong, Occasional Paper 8, 1987, 21.

https://ro.uow.edu.au/cmsocpapers/8

Research Online is the open access institutional repository for the University of Wollongong. For further information contact the UOW Library: research-pubs@uow.edu.au 


\title{
The inherent subjectivity of the apparently objective in research on ethnicity and class
}

\begin{abstract}
Policy making in the area of immigration and ethnic affairs relies increasingly on the findings of social science research. A new "conventional wisdom" is emerging in sociological and economic studies. Its claim to objectivity is based on the use of a methodology which emphasises the use of sophisticated statistical methods, especially multiple regression models. The present paper suggests that this apparently objective approach is actually based on a set of of subjectivist and voluntaristic assumptions on: the nature of society, the character of the groups being examined, and on the practice and logic of scientific research.

This type of analysis leads to the reconstitution of the "ethnic group" through the use of dummy variables, which mask many of the specific structural features of labour migrants. Moreover, the emphasis on multiple regression models makes it necessary to quantitify the variables to be examined. This involves a subjective decision by the researcher: either to give a numerical value to something for which there is no single correct form of quantification, or to exclude it altogether from the analysis.

The approach is based on a human capital model, in which migrants are seen only as economic subjects in a rational market system. This blocks historical understanding of the way labour relations function in capitalist societies, in particular of the significance of labour migration, and of the role of segmentation of the labour market according to ethnciity and gender in class relations.
\end{abstract}


THE CENTRE FOR

MULTICULTURAL STUDIES

-

UNIVERSITY OF WOLLONGONG 
The Inherent Subjectivity of the Apparently

Objective in Research on

Ethnicity and Class

S. Castles \& A. Jakubowicz

Occasional Paper No.8

\section{THE INHERENT SUBJECTIVITY OF THE APPARENTLY OBJECTIVE IN RESEARCH ON ETHNICITY AND CLASS}

Stephen Castles

A. Jakubowicz

CENTRE FOR MULTICULTURAL STUDIES UNIVERSITY OF WOLLONGONG

P.O. Box 1144 Wollongong, NSW 2500 Australia

Phone: (042) 270780 


\title{
THE INHERENT SUBJECTIVITY OF THE APPARENTLY OBJECTIVE IN RESEARCH ON ETHNICITY AND CLASS.
}

\author{
Andrew Jakubowicz \\ Department of Sociology \\ Stephen Castles \\ Centre for Multicultural Studies \\ University of Wollongong \\ PO BOX 1144 WOLLONGONG 2500 NSW
}

\begin{abstract}
Policy making in the area of immigration and ethnic affairs relies increasingly on the findings of social science research. A new "conventional wisdom" is emerging in sociological and economic studies. Its claim to objectivity is based on the use of a methodology which emphasises the use of sophisticated statistical methods, especially multiple regression models. The present paper suggests that this apparently objective approach is actually based on a set of of subjectivist and voluntaristic assumptions on: the nature of society, the character of the groups being examined, and on the practice and logic of scientific research.
\end{abstract}

This type of analysis leads to the reconstitution of the "ethnic group" through the use of dummy variables, which mask many of the specific structural features of labour migrants. Moreover, the emphasis on multiple regression models makes it necessary to quantitify the variables to be examined. This involves a subjective decision by the researcher: either to give a numerical value to something for which there is no single correct form of quantification, or to exclude it altogether from the analysis.

The approach is based on a human capital model, in which migrants are seen only as economic subjects in a rational market system. This blocks historical understanding of the way labour relations function in capitalist societies, in particular of the significance of labour migration, and of the role of segmentation of the labour market according to ethnciity and gender in class relations. 


\section{Introduction}

Chris Hurford, the Australian Minister for Immigration, announced recently that he had "the objective view for the future" on immigration. In a speech to a joint Committee for the Economic Development of Australia [CEDA] and Department of Immigration and Ethnic Affairs Forum on Immigration and the Economy in Sydney on June 11 1986, Hurford claimed that empirical and historical evidence showed that the medium and longer term benefits of immigration outweighed the costs. This evidence was drawn from research carried out over a number of years for CEDA, a business group concerned with the increased profitability of Australian private enterprise. The effect of this evidence was to bolster the government's commitment to expanding immigration and actively recruiting young, skilled, educated and employable immigrants whose presence would effectively pay for family reunions, and for the ageing sector of the population. In addition they would ensure the importation of the skills, capital, ideas, motivation and education necessary for the "post-industrial technically sophisticated society ahead...(one which is) increasingly dependent on financial and commodity markets and prices determined elsewhere" [Hurford 1986, p. 2-3].

Hurford's "empirical evidence" and the assumptions and methods utilised by those who constructed it have important consequences for Australian society. For instance, they formed the basis for a major intervention recently by Australia in the OECD on immigration and employment [Withers 1986]. David Lander, Senior Assistant Secretary in the Population and Research Branch with the Department of Immigration and Ethnic Affairs, sprang to his Minister's defence in face of a recent attack on the policy by Jock Collins - and used Withers and the CEDA study to help mount the defence [Collins 1986, Lander 1986].

At its heart the claim to "objectivity", to "scientific status", masks a deep political commitment to a view of Australia as a free market in which social mobility is a function of individual endowments and capacities, and in which the resulting outcomes are rational and "right". This commitment is rooted in a paradigm that is confused, partly tautological, and ultimately subjective. This paradigm has manifestations in a range of social sciences, the most important of which for our purposes are economics and sociology.

Our testing of this paradigm is based on an awareness that there are (at least) two competing views of what the relevant questions are to ask of Australian society. On the one hand, the claims to objective facticity rest on a proposition that Australia is a liberal democracy with significant but not endemic inequalities of income, status and power, in which all social facts are testable by the market, and in which there is broad consensus that these market outcomes represent rewards for differing personal endowments.

On the other hand, we claim that Australia is a capitalist democracy, in which the fundamental dynamic is not individual mobility (which may indeed occur), but rather the relations of exploitation between classes and the tensions and patterns they produce. The important questions to ask are those to do with the way in which Australian capitalism sustains itself by 
the constant replenishment of the pool of new immigrants, who absorb unemployment, produce high rates of surplus value, and are plastic and mobile. It is just because the process of settlement allows immigrants over time to increase their resistance against these processes [e.g. Lever Tracy 1984 ] that some mobility occurs, thereby requiring ever more new workers for the machines of capital. Indeed Ross Gittins, Economics Editor of the Sydney Morning Herald has argued that immigrants should be brought into the economy because of the jobs they appear to create in industries that they do not enter - again using the arguments so appreciatively accepted by the Minister for Immigration [Gittins 1986].

This debate is well known in the social sciences internationally, and little purpose might be served in repeating it once more, were it not for its central role in "evidencing" policy positions by government $A$ version of the debate surfaced momentarily in the pages of Search, the ANZAAS journal, some three years ago: Kelley and McAllister [1983b], utilising" new causal theory" , an approach based on manipulation of numerical data, proposed some findings about the nature of class in Australia. They characterised their "standard quantitative paradigm" as possessing three main elements:

The use of reliable and representative qualitative data, largely from censuses or large-scale, nationally representative sample surveys; precise and detailed measurement, notably of class and related variables; and the use of powerful statistical methods, especially multiple regression and related general linear-model techniques.

There was a response from Connell, arguing that they exposed their ignorance of the history of the concept of class, of its use, and of the whole of Weberian and Marxian European and Australian social research [Connell 1983]. A short, tough retort followed, claiming that Connell was trapped in the past and that sociology only became scientific in the mid1950s, having now achieved the status of a "normal" science, after Thomas Kuhn's useage of the term [Kelley and McAllister 1983c].

The methods of Kelley and McAllister, and colleagues such as Lancaster Jones [Jones and Kelley 1984] and Evans [Evans 1984, Evans and Kelley 1985], have close similarities to those utilised by the economic generators of Hurford's "objective" view. In this paper we propose to identify the approaches and findings of a selection of researchers who use mathematical techniques - the new causal theory in sociology and human capital theory in economics - to explore the mobility of immigrants in Australia, and their impact on economic and political processes. We will then argue that the paradigms contain some unjustifiable assumptions, and further suggest that even within the terms of paradigms there are major problems which these approaches fail to resolve.

\section{Socio-Economic Attainment}

In a paper published in 1984, Kelley and McAllister set out to present "an empirical analysis of the socio-economic attainments of immigrants in Australia and the effect of socio-economic position and birthplace on their voting patterns" (!984a: 388), using data from the 1973 Australian National University Social Mobility Survey. (Here we shall only look at the findings on socio-economic attainment, as the issue of political behaviour is dealt with more thoroughly elsewhere). Analysis was based on ordinary least squares regression methods, which assume "that relations among 
variables are, to a reasonable approximation, linear and additive" (p. 390). This involved the quantification of a large number of variables concerning demographic characteristics, personal and family background, support for political parties and socio-economic attainment. Now it may be acceptable to present age, gender, income or years of education as interval numbers (even that needs consideration, as different types of education may have effects not simply related to their relative duration), but the quantification of class position or occupation is problematic. To reduce the class relationship to the score $1=$ large capitalist, $0.5=$ small capitalist, $0=$ worker, ignores the complexity of class position and consciousness, and of the dynamic process of class interaction. The division $1=$ supervisor and $0=$ worker is also a gross oversimplification. The use of a linear scale for occupational status is also problematic, as will be discussed in section $6 \mathrm{~b}$ below.

Kelley and McAllister find that migrants are not generally disadvantaged, but that certain "occupational and ethnic groups" are (p. 401): in particular Mediterranean migrants - and especially to those with relatively good education. They reject the explanations that this is due to individual discrimination, or to employers' recruiting an industrial reserve army. Instead, they assert that:

...immigrants face no disadvantage in competing for jobs or in the earnings they receive for their labour and that they get the same jobs and pay as do native born workers with equal skills, knowledge and experience, and the like. (1984a: 401)

But, they go on, immigrants are generally less productive than the native born. They lack skills and knowledge. Therefore their lower status and income is a product of objective market forces. Moreover, education in the Mediterranean countries is lower in quality than in Australia. That is why educated people do less well, upon migration, while those doing manual jobs, where education and language is not needed, are less disadvantaged. "Hence in the first generation, immigrants will not do as well economically as natives but in the second they will."

There are some problems about these conclusions: first, they seem to have little to do with the "powerful statistical methods" but rather to be fairly speculative. The empirical analysis presented is supposed to give clear answers to specific questions, but the sweeping conclusions drawn from the evidence go far beyond these. Secondly, The use of 1973 data, to assess migrants' position in 1984 is questionable, especially in view of the intervening recession. It may contribute to the development of of "normal science", but it is not much use for practical purposes. Thirdly, there is a circularity in the logic: Mediterranean migrants with education do less well than they should, therefore there must be something wrong with the education. But no empirical evidence presented to show that this is the case, nor to assess its quantitative effect. The same goes for occupational status and earnings in general: if migrants do less well than the nativeborn, then their productivity must be lower, but no evidence is presented for this assertion. These problems are not surprising if one looks back at the introductory remarks, where Kelley and McAllister state their belief that postwar migration to Australia "appears, at least on the surface, to have engendered few visible socio-economic problems and almost no political consequences" (p. 287). 


\section{Second Generation Mobility: the other big Issue}

The "success" of the migration program has often been argued as lying in the social mobility of the second generation. Simply put, if the children of the unskilled and entrapped proletariat can make their way into the middle class, then the vitality and opportunity that Australia has claimed to offer the immigrant in return for low social status and heavy hard and dangerous work will have been realised. To show social mobility, it is enough to demonstrate that the children of ethnic minorities move to higher social status or occupational status locations in society than their parents; a second ingredient seeks to show that they do better than the "ocker" Australians, controlling for the occupational location of the parents.

Birrell and Seitz [1986] have argued that there is a dominant myth in Australia that a specifically ethnic underclass exists. The myth depends on assumptions of second generation ethnic failure which gives, they claim, a deterministic and essentially false picture of actual achievement. Having considered studies of Census data and university entrance data, they propose that ethnicity is not a disadvantaging characteristic, but may indeed be of considerable advantage vis-a-vis the Anglo-Australian population. Using figures which examine the occupational status of second generation males from the 1981 Census, they conclude that the overrepresentation of such people from ethnic backgrounds in high status locations confounds those who propose an ethnic underclass.

However they avoid listing data from the same tables on unemployment rates. Data produced by the National Institute of Labour Studies indicates that "most [second generation groups] had levels of unemployment not only in excess of the other Australian-born population but also of their corresponding first generation populations" [Wood and Hugo 1984, p. 33]. Second generation Greeks may have a higher concentration in Professional and Technical occupations than children of native born parents, but they are also over-represented by 65 per cent amongst the unemployed, while second generation Yugoslavs are overrepresented by 163 per cent among the unemployed.

The issue of mobility and openness of Australian society presents us with an interesting dilemma. The new causal methodology, and the analyses based on more simple cross-tabulations as advanced by Birrell and Seitz, are directed at a particular set of policy positions, namely those which seek to overcome alleged disadvantages suffered by second generation ethnic Australians. We would suggest that the internal process of polarisation within ethnic collectivities is an issue requiring sustained intellectual, theoretical and empirical effort. But can the approach and the methodologies adopted by Birrell/ Seitz achieve these goals? We think not. Quite simply, while Birrell's Monash University may have significant numbers of sons of Italian and Greek working class fathers, so too do the dole queues. If both these elements are features of the second generation experience, it is fairly slipshod to concentrate on only one of the elements and reach conclusions thereby, which have as their policy goal the withdrawal from addressing the particular needs of poor children of "ethnic" origin. 
A more detailed analysis of the 1981 Census data carried out by lan Burnley [1986] in the Sydney metropolitan area attempts to address a similar question regarding an ethnic underclass - using the concept of structural pluralism as the entry point. Structural pluralism exists in this version (which is not the same use of the term as in Jean Martin's The Migrant Presence), when, over two generations, low or high occupational status is "inherited" by the children of particular ethnic/religious groups. The test is the degree of similarity of occupational profiles between generations, and the residential concentration of ethnic groups over generations - an approach drawn from the social ecology of the early twentieth century Chicago school of social science.

\section{Burnley reinforces Birrell/Seitz by showing that}

the second generation of those immigrant groups which were more concentrated in low-socio economic status occupations were less concentrated in such occupations than those second generations whose parents' occupational profile compared to that of the host society....[T]here was almost full occupational convergence between groups and the host society in the second generation....[Burnley 1986, p. 79]

Burnley's findings suggest that ethnic collectivities have quite specific mobility trajectories in the second generation. But these are not somehow "ethnic" versus non-ethnic. There are significant differences between groups which are noted but not theorised. The differences between men and women are also marked - with the major movement for young women (compared to their mothers) from labouring/process work to clerical and technical occupations.

Burnley's contribution to an analysis of why this might be occurring is to advance Banton's "rational choice" theory of migration [Banton 1983], wherein " the world is made up of self-interested groups and individuals each intent on the maximisation of social and economic benefits and the minimisation of costs..." such that the children of immigrant parents have been encouraged to "compete as individuals, and such competition, according to Banton, diminishes racial and ethnic boundaries" [ Burnley 1986, p. $80-81$ ]. At least the basis of the position is clear, though Burnley too does not provide unemployment figures to allow us to examine the opposite end of the ethnic take-off phenomenon. Burnley's data shows significant movement into clerical, professional and technical occupations by second generation Greeks, Italians and Yugoslavs in Sydney. But also significantly, access to managerial and administrative jobs, the potentially powerful decision making positions in a bureaucratic society, is still fairly limited and shows, for the most part, the greatest discrepancy between Ocker and ethnic young workers. [Burnley 1986,73-76].

This question of the second generation has intrigued researchers and policy analysts alike, much as it did in 1960 when Justice Dovey chaired the Immigration Advisory Council study of immigrant children, discovering (without any valid empirical data) that 95\% were "assimilating well". Given the high incidence of youth unemployment, the government sponsored Institute for Multicultural Affairs carried out a major study of the needs of ethnic minority and immigrant youth in relation to the labour market programs offered by the government. The Institute listed a number of the 
key proponents of the new causal theory as consultants on this major study of migrant youth unemployment, Reducing the Risk [AIMA 1985].

The causal path analysis used produced little in the way of startling insight. All the factors identified left $91 \%$ of the variance unexplained among Australian born, $92 \%$ among the Overseas born with more than five years residence, and $86 \%$ among Overseas born resident less than five years. This latter group, particularly those with poor English language skills, were the group most likely to be unemployed [AIMA1985, p. 65]. No specific birthplace factors were significant, suggesting that specific discrimination (i.e. irrational rejection of people because of their ascriptive endowments or characteristics) was not taking place. The implication was that it was most likely to be characteristics of the individual who was unemployed rather than the economic relations in which s/he was enmeshed, that was the most significant contributor to the state of unemployment.

The conclusions that have been drawn by analysts fascinated by the success of ethnics, has served to disguise a number of important features of these trajectories. Inside ethnic communities the range of experience is vast and cannot be ascribed to ethnicity in any useful way. Moreover, the failure of the education system to address the learning needs of working class children, a significant component of whom are of ethnic origin, is a more pervasive porblem that cannot be swept away by simply labelling the issue as "mythical" or the problem (whatever it is ) as "solved".

\section{IMMIGRANT GENERATION AND INCOME}

Chiswick and Miller (1985) use microdata for adult men from the 1981 Australian Census to examine relative incomes of first and second generation migrants compared with the rest of the male population, and to assess the determinants of these income levels. The dependent variable in their estimating equation is the natural logarithm of income, and the explanatory variables are education, labour market experience, qualifications, urbanisation, marital status, government employment, and various factors specific to migrants, including language use, length of residence, citizenship and education after arrival. The model contains no information on hours worked or type of employment.

Chiswick and Miller find that the overseas born have 5\% lower income than the Australian born. However, if schooling, labour market experience, marital status and location are held constant, the incomes of the overseas born are $7 \%$ less than the native born. Increasing duration of residence has a positive effect on income, but only a small one, so that it would take 50 years of residence to completely close the gap. (p. 545) Education and work experience bring lower returns for migrants than the native born, and this disadvantage is particularly marked for those from non-Englishspeaking countries. Chiswick and Miller compare the incomes of different birthplace groups, and find that there are substantial variations: compared with migrants from the UK and Eire, Southern Europeans have $18 \%$ less income, Western Europeans have 9\% less, Eastern Europeans $12 \%$ less, people from the Middle East $16 \%$ less and Asians 8 per cent less. This important finding is relegated to a footnote (1985: 548). 
They then go on to look at the incomes of men with migrant parents, in comparison with those with both parents of Australian birth. They find that differences in schooling, labour market experience, marital status, qualifications and government employment are all quite small. The main difference is that Australians of foreign parentage are more likely to live in large urban areas. Second generation migrant men are found to have on average $4 \%$ higher incomes than Australians with Australian born parents. If other variables are held constant, the difference falls to a statistically insignificant $1 \%$, implying that second generation migrant men are doing as well as other Australian men. In general they state:

The findings do indicate that the income gap between immigrants, including recent immigrants, and the native born in 1981 was relatively small, suggesting that immigrants are still doing relatively well in the Australian labour market. In conclusion, it appears that immigrants in Australia have adapted fairly well to their new labour market and that they do not suffer inordinate disadvantages. (p. 552).

These conclusions require a few comments. First, they only make sense, if one accepts that it is valid to compare the situation of all migrants taken together with the Australian born. In fact, this comparison is of little value, as the various birthplace groups are highly diverse, with UK and Eire and other Northern European migrants having similar situations to the Australian born, while Southern Europeans and Middle East migrants are very different. Chiswick and Miller only disaggregate by country of origin at one place (see above), and the findings there makes nonsense of their general conclusions. Secondly, Chiswick and Miller may be right to say that their findings show that male migrants have for the most part done well in terms of income. But their evidence does not justify their conclusion that "Immigrants ....do not suffer inordinate disadvantages". They reduce the complexity of the labour market to just one variable: income. What about type of work, hours worked, multiple employment, working environment, job security and unemployment? All these dimensions are simply ignored. Can one say that migrants are doing well, if they are forced to work long hours in heavy, unhealthy and insecure jobs to get a reasonable income? There is a lot of evidence for occupational disadvantage of migrant workers from Southern Europe and the Middle East countries, and particularly of women from those countries, who are not covered by Chiswick and Miller's study at all. Another important issue is the high rates of unemployment of migrant workers, particularly of the newly arrived, but of older established groups too. As for the second generation, there is indeed evidence of upward occupational mobility, and of improvements in educational level compared with the migrant generation. But as already mentioned, Census figures also show above-average rates of unemployment (see Wood and Hugo 1984: 30), and more recent statistics show that second generation migrant youth has been hard-hit by the recession of the early eighties (AIMA 1985: 43).

\section{Political Behaviour}

In a further article, Kelley and McAllister (1983a) turn their attention to the voting behaviour of migrants in Australia, seeking to analyse changes over time in the voting habits of three major birthplace groups. Data come from three large national surveys: the Australian National Political Attitudes Survey of 1967 and 1979, and the 1973 ANU Social Mobility Survey. The 
method is essentially the same as already described, using ordinary least squares regression methods. Again, there are variables for family background and for socio-economic status. This time all capitalists are scored 1 and workers 0 (what happened to the small capitalists?). Overseas born persons are divided up into three categories: Mediterranean, Eastern European and Northern European.

McAllister and Kelley find that there is no "Northern European" vote. The actual slight propensity of $\mathrm{N}$. Europeans to favour Labor can be explained by their background and socio-economic status. "It seems that the irrelevance of ethnicity for Northern Europeans is an enduring aspect of Australian politics". (p. 102). Eastern Europeans, on the other hand have a tendency not to vote Labor, which cannot be explained by background or socio-economic status: "The effect of ethnicity is, however, substantial, producing a swing of $9 \%$ against Labor, on the average". In the case of Mediterranean migrants, McAllister and Kelley find a sharp change between 1967 and 1979. In the late sixties, they were less likely to vote Labor than native-born Australians, later they were more likely to. Again, this cannot be explained by background or socio-economic status. "...across the whole period there was a change in the effect of Mediterranean ethnicity per se: up to the early 1970 s, it led to roughly a $10 \%$ swing against Labor, while by the late 1970 s, it produced a swing of about the same magnitude in favour of Labor." (P. 103).

The authors then put forward two hypotheses to explain these findings: first, that length of residence in the country accounts for the change through its importance in political assimilation, secondly, that the timing of the immigrant's first vote is decisive (p.104). The first implies that as migrants get more assimilated, they become more politically mature, and therefore vote for conservative parties. The second implies that once migrants establish a party preference, they are too stupid to change, even if a different party might represent their interests better.

Once again, a set of dummy variables is created and the computers are set in motion. In fact, McAllister and Kelley find no evidence to support either hypothesis and therefore reject them. They then speculate that Eastern Europeans might vote for conservative parties, because "they are reacting to the communist regimes in their homelands". And Mediterranean voters may favour Labor, because they like the policies of multiculturalism, first introduced in the Whitlam era. (P. 105). No doubt they are right, and there is a lot of evidence to support this view. But what has this got to do with "modern sociology" and "powerful statistical methods"? Kelley and McAllister state wistfully: "Unfortunately the data at hand has no items that would tap such perceptions directly, so the claim must remain a speculative but highly plausible explanation". (P. 105).

More serious is the violence Kelley and McAllister do to the concept of ethnicity. It is meaningless to speak of Northern European, or Eastern European or Mediterrean ethnicity. How can, say Irish and German culture and history be subsumed under one category? And if it could, what would its explanatory value be? Kelley and McAllister's "Mediterranean ethnicity" includes both Yugoslavs and Turks - extremely varied groups, with different religions, political cultures and histories. There is no meaningful 
way of lumping them together. Indeed, anyone who knows this field would refrain from even using the term "Yugoslav ethnicity", for there is no such thing, but rather a collection of loosely linked national groups (the Serbs, Croats, Macedonians, Slovenes, etc). To have disaggregated more, would have given more meaningful results, but it could not have been done on the basis of Kelley and McAllister's data: for example, in the 1979 survey, the "powerful statistical methods" were based on just 415 overseas-born persons. Going on the 1981 Census, that means there should have been about 21 Yugoslavs, 38 Italians and 7 Lebanese in the sample. Indeed, it may well be asked if that was sufficient even for the level of disaggregation they used.

\section{Migration as Development Aid}

The economist Glenn Withers recently presented an important paper, as Australia's representative at an OECD conference on migration (Withers 1986). Amongst other things, it contains an up-to-date summary of the work of the Centre for Economic Policy Research of the ANU, and of similar approaches in this area. In Section IV of the paper, Withers refers to the works of Broom et al., McAllister and Kelley and Chiswick and Miller, which we cover in the present paper, as well as to a large number of other works . Reading this helps one to understand how a "conventional wisdom" (in Galbraith's sense) develops: reference is made simply to the conclusions of the large numbers of studies cited. There is little or no discussion of the accuracy and appropriateness of the data used in these studies, nor of the methods of analysis. The conclusions of these studies (which, we would argue, are often wrong or misleading) thus become "social facts" or "the state of the art", to be cited by further academics, and to be presented to policy-makers in even more simplified forms.

For reasons of space, we will not address most of the issues raised by Wither's paper here, but confine ourselves to one topic: Withers resurrects the hoary old argument that transferring the labour power of underdeveloped countries to industrial countries is actually doing the former a favour:

This can be viewed as an equivalent to foreign aid whereby overseas-

born persons are permitted to relocate in Australia rather than Australia providing them with claims on resources. As such it well exceeds the

international foreign aid goal of one per cent of GDP. (P. 24)

Aren't we Aussies nice! Withers arrives at this conclusion through a "new measure of present resident economic welfare (PREW)" which he has developed. This shows that: "Immigrants to Australia have experienced much higher real income growth by immigrating than they would have experienced, on a weighted average, in their countries of origin" (p. 24). The argument that the recruitment of labour for advanced industrial countries in underdeveloped areas was a form of development aid, was very popular among employers and labour market authorities in the sixties. The claim was that the departure of unskilled workers would help to relieve unemployment, improving incomes and stimulating economic growth. While abroad the migrants would learn skills which they would be able and willing to apply upon returning home. In their absence, their savings and remittances would be used to set up modern industries in key sectors. (See Castles and Kosack, 1973, pp. 408-420.). Even then, the reality was different: the workers recruited were mainly young and 
dynamic people, often with the industrial skills and experience needed for development, rather than the unemployed and underemployed rural masses. Emigration of labour was becoming a constraint on development, so that Yugoslavia, Greece and Spain actually started taking countermeasures. By the early seventies, there was a general realisation that emigration of labour led to structural imbalances, and hindered, rather than encouraged development. The ILO set up a world employment programme in 1974 to seek ways of transferring industry and employment opportunities to the countries from which migrant workers came (see Castles 1984)2.

The point is that both sides in the debate were conscious that it is necessary to examine a whole variety of factors: the employment situation and qualifications of migrants before departure, the effect of migration on local and national labour markets, effects on productivity, investment, wages and commodity prices, and the effects of migrants' remittances and the use of their capital upon return. The problem of Wither's argument on this issue is not so much that he seems unaware of this whole debate. It is rather that he can only define migrants' income growth in Australia as a form of development aid, by making the unspoken assumption that this has some sort of spin-off for the countries of origin. However he does not demonstrate this in any way.. So the mere probability that migrants earn more in Australia than they would have if they had stayed in their countries of origin, is taken for proof that employing migrants in Australia is equivalent to development aid. This is the way that "normal science" creates ideology.

\section{Problems of the Paradigm}

In looking at various contributions of the "modern sociologists" and the human capital theorists to the study of the situation of migrants in Australian society, we have made some specific criticisms. It is now necessary to get to grips with some of the basic problems of this paradigm.

\section{a) "Normal Science".}

The use of the term "paradigm" to discuss what people do in the social sciences is contentious, to put it mildly. Thomas Kuhn, when discussing the emergence of scientific revolutions specifically, indicated that his concept of paradigm was peculiarly inappropriate for the social sciences. Be that as it may, it was not long before the approach Kuhn has taken to physicists and chemists was turned to focus on sociologists and other social scientists. Robert Friedrichs adapted Kuhn's approach to a survey of American and European sociology in 1970, postulating two major schools of conflicting thought - represented by modes of thought about what social scientists did. He labelled these first and second order paradigms. "The fundemental paradigmatic dimension [in a social science hinges on] the grounding image the social scientist has of himself as a scientific agent" [Friedrichs 1972, p. 55].

For Kuhn scientific revolutions occurred when "normal science", defined as the creation of understanding "within the confines of a single paradigm, a relatively 'classic' study or experiment that has been sufficiently compelling to shape a discipline's sense of where its problems lie, what its appropriate tools and methods are, and the kinds of solutions for which it might settle"[ 
Friedrichs 1972 , p. 4]. Revolutions occur when competing gestalts redefine crucial problems, introduce new methods and establish uniquely new standards for solutions. "At the moment of polarisation", writes Friedrichs, "the devices and procedures that mediate differences in perspective and evidence in 'normal', non-crisis science fail"'[1972, p. 2].

McAllister and Kelley claim that the revolution has occurred, the preparadigmatic nonsense and confusion has been demonstrated as passé, and that new causal theory is now 'normal' science. Its normality lies in its effectively undisputed hegemony as the mode of discourse and dominant paradigm in social research. Its methods are able to resolve most contentious social issues and the failure of the previous approaches to do so has been revealed. Any questions that cannot elicit quantifiable solutions are seen as irrelevant - or at least unscientific.

So what are the criteria of validity within the "normal scientific" paradigm? Menzies notes that there are seven main conditions that have to be met if the method is to achieve what it seeks. The functions should be linear, with any interactive effects noted and countered. The model should be recursive, and avoid feedback loops. The causal direction of the variables can be specified, so that antecedents and outcomes can be identified. Error terms should be uncorrelated. The assumptions of multivariate analysis as to the interval scaling, homoscedasticity (error term has constant variance), and absence of multicollinearity, must hold. The measuring instruments should be reliable, while dummy variables are assumed to be point variables [Menzies 1982, p. 157ff]. Is it possible to restrict the analysis of society to such data? We argue that this leads to a reduction of social reality, eliminating many central factors.

\section{b) Class Composition}

For instance, an important problem arises from the necessity to have interval data. This leads to the development of hierarchical scales (e.g. occupational status) which assume that occupational differences represent hierarchies of agreed value. What does an occupational hierarchy represent? It is after all an unlinear scale in which an occupation at point 50 has twice the "status" of one at point 25, and half that at 100 . Yet when people are given the opportunity to talk about their responses to different jobs they give different answers depending on whether they are asked for their own perception, or what they believe the general public perception is. Public knowledge about occupations reflects not the actual power relationships or opportunities associated with them, but the access people have to information about those jobs. In reality status scales are based on subjective assessments arrived at through sample surveys, and are merely a reflection of popular perceptions of social ordering in a given society. The magic effect of the method is that numbers arrived at in such a subjective and arbritary way can become the data-base for sophisticated mathematical procedures, which then convey an appearance of scientific objectivity to the the coefficients which tumble out of the computer.

The "modern sociologists" argue that status hierarchies remain unchanged over long periods. However, Wright and Singelmann [1982] have traced the changes in the content, power and autonomy of various jobs in the United States labour market over the period 1960 to 1970 . They argue that 
occupational locations are fairly poor indicators per se of social class, and have proposed a reconstruction of both industry and occupational categories in the Michigan Survey Research Centre and US Census data they have used. The effect of this detailed reworking is to generate an emprically based class structure model which when elaborated, demonstrates some crucial changes in the internal composition of classes over time.

The destruction of small business and the petty bourgeoisie have been characteristic of the changes in industrial structures, similar to changes which have taken place in Australia in the decade 1970 to 1980 . The implication for Australian ethnic minorities of these sorts of changes is that the petty bourgeois pathway to mobility is closing off. Managerial class locations expanded greatly in the decade. That is, with the declining proportion of jobs available in traditional industrial sectors, the vast majority of new jobs opening up were so-called white collar jobs, which were traditionally associated with higher status because of their identification with greater autonomy,power, responsibility and freedom for the workers involved. However, the evidence from the US indicates that there was:

a systematic tendency for those positions with relatively little control over their labour processes to expand during the 1960s, and for those positions with high levels of autonomy to decline... a continuing process of proletarianisation does characterise advanced capitalism [Wright and Singelmann 1982, p. 198].

Thus the meaning of occupational locations may well have changed to match these recompositions of the classes over time. White collar and similar jobs with managerial status historically, are becoming in practice "working" class. The unilinearity and underlying assumptions about what the hierarchy is supposed to represent does not appear able to cope with these sorts of factors. The occupational hierarchy may be forced into an interval form, but the effect of doing this may well be to render results based on the practice seriously misleading. Consistency of methodology amongst researchers simply magnifies the nonsense. It does not "prove" the ladder is socially real.

c) Ethnicity and Gender.

The paradigm refers to the notion of "ethnicity", and as Burnley points out [1986, p. 66], in fact utilises the surrogate of birthplace to represent ethnicity. It is then assumed that ethnicity is a point variable (as it has to be, to be included as a dummy variable in path analysis): you are either ethnic or not ethnic, a forced choice, which is open to point form specification. It is clear that for some ethnicities or birthplaces, language skills in English will be almost collinear: i.e. birthplace and English language skill will be closely correlated. In others however the relationship will be very different, and may vary highly. To introduce a dummy variable such as this into a hypothesis about language and education, and their effect on income, and discover it has little if any effect, may simply demonstrate the collinearity of the factors. When such a problem is overlaid by data set problems, both of sample size and reliability of the Census data drawn from non-English speaking populations, or populations with limited English language skills, 
the fulfillment of the basic requirements of the paradigm can be shown to be suspect.

The major findings of Broom et al., [1980] Kelley and McAllister [1984a] and the other quantitative sociologists is that there is little or no discrimination in the Australian labour market any more - simply a response to the endowments of language and education brought by immigrants. Over time the children of non English speaking immigrants from southern Europe do rather well in Australia, compared with not only their parents but also their Anglo-Australian peers. Having consumed this material one is tempted to agree with Poloma who notes in her review of causal path analysis techniques, that "any theoretical aspect of path analysis is a statistical problem rather than a sociological one"[Poloma 1979, p. 136].

Is social mobility for immigrants then not occurring? Clearly, the changes documented by these researchers have occurred. Are they correct then to argue that Australia is a liberal democracy with an open opportunity structure? Our answer is that this approach conceals more than it reveals of Australian society. Hidden within the findings and disguised by the approach are two major issues: class relations and gender exploitation.

Regression analysis, used in the papers referred to, decomposes the actual group characteristics of migrant populations. By holding specific characteristics constant in the name of comparability (such as age, education, previous experience), the historical process of recruitment of migrant labour is made meaningless. The whole point about labour recruitment is that it does not lead to migrant populations similar in characteristics to the host population. Typically, it is a movement of young economically active persons, generally with a male surplus. The economic and educational characteristics depend on the selection processes of the receiving country, and these are motivated by the economic and demographic interests of those in power there. This type of analysis tends to show that migrants are not discriminated against - their poor socioeconomic position is due to the fact thay they have inferior characteristics (= lack of human capital). Their inferior situation is shown as fair, because it is a product of structural market forces, rather than of discrimination (for an exception to the way this method is used see Shergold 1984). But the uneven development of the world economy, and people's lack of human capital is itself a result of past inequities and discriminations. However, this problem simply does not arise for the modern sociology/human capital paradigm. It is, within the scope of its logical and methodological assumptions, literally unthinkable.

Immigrant women experience Australian society in ways which are significantly different to men. Broom et al. [1980] report only the male experience; the concept of work they use is devoid of awareness of domestic labour, and necessarily can say little about crucial areas of women's paid employment, such as outwork. Evans [1984] addresses herself directly to immigrant women, yet also appears oblivious to the issues of domestic labour and of outwork. The latter also reveals some of the more nonsensical elements in the occupational hierarchy approach to status attainment. In a discussion of female "entrepreneurs", [1984: 1081- 
1082] Evans demonstrates that married Mediterranean women with low educational backgrounds are more likely to be "entrepreneurs" than educated unmarried Australian women. This interesting phenomenon is explained as follows: "high achievers who lack educational credentials may find their careers stymied in bureaucratically organised firms, and so strike out on their own". An alternative explanation is that outworkers are perceived as "self-employed", (higher status than employee!). The 30,000+ women are employed as outworkers in the clothing industry in Australia, are less likely to be "high achievers" escaping bureaucracy than low paid women forced to accept machining at home. Disguising exploitation as freedom may be the result of the methods used, but the ideological effect is clear.

The conclusion on this reached by Evans, that "Mediterranean women are the least likely to be in the labour force, have fairly low unemployment rates, occupy the lowest status positions and receive the lowest wages" [1984:1084] suggests a compounding of the problem. Many women will be working in family situations, as unpaid workers creating value, as outworkers, and as domestic workers. They are unlikely to be formally seeking work, because they are fully occupied. The labelling of their experience as "entrepreneurial" is a mockery.

\section{d) The Concept of Society}

The "modern sociology" and "human capital" approach reduce the complexity of human interaction, the role of historically-mediated social institutions and the significance of values, norms and culture to a set of mechanistic and quantifiable relationships. To be acceptable, these must be suitable for "precise and detailed measurement", and for application of "powerful statistical methods" (Kelley and McAllister, 1983b). In other words, the object matter of sociology is not to be defined by the epistemological interest of the researchers (or of social groups or institutions), but by the method. Anything that cannot be accurately measured - and that is most of social reality - is to be eliminated from the discipline. Society as an on-going and complex historical totality is clearly not measurable, and therefore does not exist for "modern sociology". The circular logic we noted above in some examples is a product of this concept of scientific method. Adorno pointed to this dilemma about thirty years ago (indicating incidentally that this debate is not as modern as some would have it):

The procedure of operational or instrumental definition generally current in empirical techniques......sanctions the primacy of the methods over the object, and ultimately sanctions the arbitariness of the scientific enterprise itself. The pretence is made to examine an object by means of an instrument of research, which through its own formulation, decides what the object is; in other words, we are faced with a simple circle. (Adorno 1976, p. 73).

Kelley and McAllister actually see the primacy of the method in their paradigm as an advance: "The central developments in the quantitative revolution are conceptual and methodological; the descriptive details on the United States or Britain are peripheral". [1984b, p. 111). The aim of "modern sociology" is to have good (= normal scientific) methods, not to understand society. Or as Adorno put it: "The method is likely both to 
fetishise its object and, in turn, to degenerate into a fetish." (Adorno 1976, p. 72).

Sociology can only be an historical and interpretative science, because every social interaction, social institution or social norm is a product of historical developments, within a totality of social relationships. You cannot adequately grasp the situation of Turkish worker in Australia without a background understanding of Turkish society, Australian society, the uneven development of the capitalist world economy, the history of ethnic relations in Australia, the structure of the Turkish family and a whole galaxy of further relationships. A Census datum on the income of this Turkish worker is an isolated social fact, which, taken on its own, is quite meaningless. Each social phenomenon is only significant in its relationship to the totality of social relationships. That is why sociological analysis is always only an approximation to reality. We are forced to simplify, in order to describe and analyse social relationships. The justification for that simplification must be sought in the relevance of the results for social action. The "modern sociologists", in their desire to attain the status of "normal science" in fact simplify even more than sociologists who use both qualitative and quantitative methods. They simply reduce their perception of the real to that which can be quantified. They postulate that they can understand a given social relationship (income or status for instance) through perhaps a dozen quantifitative parameters, linked in a multiple regression model. It looks complex and scientific to the layperson, because the mathematics give it an aura of scientificity, but such calculations are in reality a gross oversimplification of a far more complex process. and may hinder understanding of the way our society works. For instance, McAllister and Kelley dismiss the possibility of examining power relations in Australian society with the throw-away remark that "in a national sample there are too few large capitalists to matter much..." (McAllister and Kelley 1983c, p. 252) - as if the power of the capitalist class were a function of its numerical size! This does not mean that there is no place for statistical methods. On the contrary, both descriptive and analytical statistics are vital to the social sciences, but we should avoid inflated claims on their objectivity and predictive power.

\section{e) The View of Human Nature}

The methodology of "modern sociology" and of "human capital theory" implies an implicit view of human nature, in which each individual is perceived as a social atom, trying to maximise his or her economic benefit. This is based on a concept of rationality, which goes back to the roots of early bourgeois thought. It is no coincidence that Barry Chiswick starts his consideration of labour market income by praising Adam Smith's contribution in The Wealth of Nations, (Chiswick, 1974, p.11) nor that Glenn Withers sees the highest accolade for Australia's migration policy in the assertion that it "can achieve goals of which Mr. Jeremy Bentham would approve" (Withers 1986, p. 27). The human capital model abstracts from the complexity of different historical societies and groups, and studies the behaviour of rational individuals, who make informed choices to raise their benefits:

The basic framework... is one in which the returns to an individual from labour market activity are a function of his stock of training - or 'human capital'.... Since human capital is created at a cost, no one would 
willingly invest in human capital unless it generated sufficient monetary or nonmonetary benefits to compensate for the cost. The analysis of investment in human capital is part of the broader analysis of compensating wage differentials. Human capital can be acquired in several different ways. Schooling, vocational training, formal on-the-job training, learning by doing, medical care, acquiring information, and migration are means by which individuals can increase their productivity. Hence they create human capital. Unfortunately, we cannot directly measure units of human capital (i.e. productive powerThis study focuses on the monev-income-producing effects of years of formal schooling and years of labour market experience after schooling, all of which are quantifiable. (Chiswick 1974, pp. 16-17, emphasis in original).

Does this concept of the rational economic person have much to do with the realities that force people to leave their homes and migrate across the world? Chiswick illustrates his model by looking at seasonal work. $\mathrm{He}$ argues that a person will only take a seasonal job if it offers compensatory benefits: higher wages for the period worked, plus unemployment benefit for the period not worked, plus a notional value for the extra leisure time.

This simple model of wages in seasonal industries implies that jobs offering relatively less employment during the year offer higher weekly or hourly wages for the time actually worked. The higher wage compensates for less income during the period of unemployment. (Chiswick 1974, p. 16).

The model is indeed simple, and has nothing to do with the reality of the USA, where seasonal work is actually carried out by hundreds of thousands of migrant workers, mainly undocumented Latin Americans. Their wages are not higher than average. On the contrary, they are forced to accept the most appalling wages and conditions, and have no security of employment nor entitlement to the dole. This particular labour market does not depend on the rational choices of informed economic subjects, but on historical power relationships, and on state policies. This may be an extreme case, but we would argue that the human capital model can in fact contribute little to an understanding of the mass labour migrations of the last forty years, nor to an assessment of the situation of the migrants today. The model simply ignores most of the dimensions relevant for understanding the causes of migration, and the mechanisms which assign people to particular sectors of the labour market. Again, it is necessary to look at the actual structures of sending and receiving societies, at the class position of migrants before and after migration, and at the processes of uneven development which cause migration.

\section{Conclusion.}

Australian sociology has grrown in academic stature and social relevance in recent years. It may well need to re-run introspective debates which were worked through in great detail a decade or more ago in Europe and North America. The significance of these debate today is not purely academic. The influence of "modern sociology" in policy-making is on the ascendant, because the quantitative methods appear objective, and because its conclusions are generally uncritical, and do not question the existing order. There is no doubt that statistics and quantitative methods have a central place in the social sciences, but sociology as a discipline 
will not prove its maturity by a feverish striving for scientificity, modelled on the natural sciences, and based exclusively on numerical procedures. Nor will it prove its value by adopting a methodology which makes large portions of its object of investigation invisible. Sociology must look at society as a whole, and it must be critical towards its object of investigation.

We have demonstrated that these methods and the claim of their proponents to be doing "normal science" are highly questionable, even on their own assumptions. In many instances the main product of this apparently scientific method is ideology. In the debate on positivism, which occupied German sociology in the 1960s, Adorno drew attention to the corrosive implications of such approaches:

Such sociology becomes ideology in the strict sense - a necessary illusion. It is illusion since the diversity of methods does not encompass the unity of the object and conceals it behind so-called factors into which the object is broken up for the sake of convenience; it is necessary since the object, society, fears nothing more than to be called by name, and therefore it automatically encourages and tolerates only such knowledge of itself that slides off its back without any impact. [Adorno 1976, p. 76].

A century and a half ago, the founding father of "social physics", $M$. Auguste Comte, warned against the fetishisation of apparently scientific methods:

The most perfect methods may, however be rendered deceptive by misuse - and this we must bear in mind. We have seen that

mathematical analysis itself may betray us into substituting signs for ideas, and that it conceals inanity of conception under an imposing verbiage. (Comte 1975, p. 250)

The modern sociologists and human capitalists would do well to note that there is no use in getting scientific answers if the questions are nonsense.

\section{Footnotes}

1. This finding could well be explained by a segmented labour market theory of labour migration, in which policies of recruitment and employment direct migrants towards low status jobs. Clearly, the migrants with high educational and/or occupational status before migration will be most obviously disadvantaged.

2. It is curious that the experts of the OECD the ILO and the labour recruiting countries only discovered that recruiting labour from underdeveloped areas was harmful to development at the precise moment that Western European economies moved into recession, so that migrant workers were no longer wanted. Sending them home then became a new form of "development aid".

\section{References}

Adorno, T.W., 1976, Sociology and Empirical Research, in: T.W. Adorno (ed.) The Positivist Debate in German Sociology, (London, Heinemann, ).

AIMA, 1985, Australian Institute for Multicultural Affairs, Reducing the Risk, Unemployed Migrant Youth and Labour Market Programs, (Melbourne).

Banton, M., 1983, Racial and Ethnic Competition, London, Cambridge University Press. 
Birrell, R. and A. Seitz, 1986, The Ethnic Problem in Education: The Emergence and Definition of an Issue, paper presented to: AIMA National Research Conference, Melbourne.

Broom, L., et al,1980, The Inheritance of Inequality, (London, RKP, ).

Blau, P.M. and O.D. Duncan, 1967, The American Occupational Structure, New York, Wiley.

Burnley. I.H., 1976, Convergence or Occupational and Residential Segmentation? Immigrants and their Australian-born Children in Metropolitan Sydney, 1981, in: ANZJS , Vol. 22, No. 1.

Castles, S. and G. Kosack, 1973, Immigrant Workers and Class Structure in Western Europe, London, Oxford University Press.

Castles, S. 1984, Here for Good - Western Europe's New Ethnic Minorities, London, Pluto Press.

Chiswick, B.R., 1974, Income Inequality, (New York, National Bureau of Economic Research, 1974).

Chiswick, B.R. and P. W. Miller, 1985, Immigrant Generation and Income in Australia, in: The Economic Record, Vol. 61, No. 173.

Collins, J., 1986, Chris Hurford meets the ghost of Arthur Calwell, Australian Society, 5,5, May, pp. 31-32.

Comte, A., 1975, Auguste Comte and Positivism: The Essential Writings , (ed. by Gertrud Lenzer), (University of Chicago Press).

Connell, R.W., 1983, Social Class in Australia, in: Search, Vol. 14, No. 9-10.

Evans, M., 1984, Immigrant Women in Australia: Resources, Family and Work, in: International Migration Review, Vol. 18, No. 4.

Evans, M. and J. Kelley, 1985, Equality and Discrimination in the Australian Labour Market, paper present to the Population Association of America Conference.

Friedrichs, R., 1972, A Sociology of Sociology, New York, Free Press.

Gittins, R., To reduce unemployment why not increase immigration, Sydney Morning Herald, July 5, p.38.

Horan, P., 1978, Is Status Attainment Research Atheoretical? In: American Sociological Review, 43, pp. 534-541.

Hurford, C., 1986, Speech to the CEDA Forum on 11 June 1986, Canberra, Minister for Immigration and Ethnic Affairs.

Jones, F.L. and J. Kelley, 1984, Decomposing Differences between Groups, in: Sociological Methods and Research, Vol. 12, No. 3

Kelley, J. and I. McAllister, 1983a, Changes in the Ethnic Vote in Australia, 1967-79, in: Politics, Vol. 18, No. 1.

....., 1983b, Social Class in Australia, in: Search, Vol. 14, No. 3-4.

----, 1983c, Modern Sociology and the Analysis of Class, in: Search, Vol. 14, No. 9-10.

---, 1984a, Immigrants, Socio-economic Attainment and Politics in Australia, in: British Journal of Sociology, Vo. 25, No. 3.

-..-, 1984b, Letter, in: Search, Vol. 15, No. 3-4.

Kuhn, T., 1962, The Structure of Scientific Revolutions, Chicago, University of Chicago Press.

Lander, D., 1986, Immigration and Growth, Australian Society, 5,7, July, pp.4 - 5.

Lever-Tracy, C., 1984, A New Australian Working Class Leadership: The Case of Ford Broadmeadows, in: G. Bottomley and Marie de Lepervanche (eds.), Ethnicity, Class and Gender in Australia, Sydney, George Allen and Unwin.

Martin, J. 1978, The Migrant Presence, Sydney, George Allen and Unwin.

Menzies, K. 1982, Sociological Theory in Use, London, RPK.

Paloma, M., 1979, Contemporary Sociological Theory, New York, Macmillan.

Shergold, P. R. Discrimination against Australian Immigrants: an Historical Methodology, in: I.H. Burnley, S. Encel and G. McCall, (eds.), 1985, Immigration and Ethnicity in the 1980 's, (Melbourne, Longman Cheshire).

Withers, G., 1986, The Impact of Migration on Domestic Employment and Unemployment. The Case of Australia, Paper for: The Future of Migration - Conference of National Experts, 13-15 May 1986, Paris, OECD.

Wood, D., and G. Hugo, 1984, Distribution and Age Structure of the Australian Born with Overseas Born Parents, Canberra, DIEA.

Wright, E.O. and Singelmann, 1982, "Proletarianization in the changing American Class Structure", American Journal of Sociology, 88, Supplement, S176-S209. 